\title{
ANALYSIS OF ROAD ACCIDENT IN HISAR TEHSIL
}

\author{
Varun Kumar $^{1}$, Rahul Bansal ${ }^{2}$ \\ ${ }^{I}$ Assistant Professor in Department of Civil Engineering, JCDMCOE, Sirsa (Haryana), India \\ ${ }^{2}$ Assistant professor in Department of civil Engineering, JCDMCOE, Sirsa (Haryana), India \\ varuncherwal@gmail.com
}

\begin{abstract}
Accidents are caused not due to the natural process but by self disastrous mistakes. In Hisar total road length is $2221 \mathrm{kms}$ from which NH65 and NH1O passes through. Vehicle crashes are a major concern in rapidly growing urban agglomerations. The aim of the work described in thesis was to obtain a greater understanding of the problem of road accidents in Hisar. The social importance of road accidents in this city were identified by comparing deaths from road accidents with deaths from diseases thought to be of concern. A detailed study was made of road accidents in Hisar. Factors that might be contributory to the high accident rates are that Hisar is coming under developing cities were studied and due to the increasing of motor vehicle population, the accidents come more. From the study till, it can be accomplished that these Highways segment requires enhancement from protection point of analysis. A huge amount of accidents have been taking place over such an area of HisarSirsa road and Hisar-Delhi Bypass road mainly. Appropriate traffic management and organize coordination to conduct road users ensuring secure progress of vehicles has been suggested \& several of the amenities such as walker crossings and openings of medians, Acceleration-Deceleration tracks were redesigned in regulate to recover the protection of the road and decrease the accidents.
\end{abstract}

Keywords: Accident, Hisar, NH $10 \& 65$, Population, Regression, Safety, Traffic

\section{INTRODUCTION}

Accidents on road have majorly emerged as one of the biggest cause of danger or caution in the world for the past few years. It is found to be the $9^{\text {th }}$ leading cause of death in 2004 and it will be predicted that by 2030 it is the fifth foremost cause of passing away as by current rate of death. It is found that India has surpassed China for recording the highest no. of people killed in 2008 and around 1.2 lakh people exaggerated by this rate. With the study it is found that in road accidents $37.1 \%$ people involved as cause of unnatural cause of accident in the country. In a fact I found that Nagaland has very low figure of no. of accidents in the country as a state but number of persons killed with per lakh population and per10000 motor vehicle, the major brutality was highest for this state. Mizoram has $2^{\text {nd }}$ highest rate of severity of road accidents. For the accidents the number of road accidents brutality with per lakh population of India goes up 39.8 in 2004 as compare to 42.5 in 2010 , as the increasing rate of difference is 3.3 between the years 2004 2010. According to the year 2010, Goa has found to be the most accidental state of road accidents per lakh population i.e. 267. According to the year 2010, the highest no. of persons killed on road found to be in Tamil Nadu i.e. 23 as per lakh of population, than in Goa i.e. 19.1 than in Haryana i.e. 18.9. With the various studies for the accidents it is found that the accidents on roads are not due to natural cause but it is found that it will occur due to of carelessness and ignorance of road safety criteria. Environmental factor also plays a big role in cause of accidents on roads like Fog in winter seasons etc. This proposal highlighting on accident studies on the NH-10 \& NH-65 and other areas for studies which is passes through the Hisar Tehsil. For finding the major role of accidents occur on these highways several steps has to be taken for the road safety programmed and understanding the deep of the problem. The first step is to be taken that good and real data has to be collected with real crashes on roads that second is we have to understand the variability of the data and what is the reason behind the accidents and injuries and what would be the possible steps to outcome to avoid these accidents. The main focus of this study is to reveal the methodology development and find relation with population and accidents.

\section{OBJECTIVES AND SCOPE OF STUDY}

- To study the various collapse characteristics in Hisar Tehsil causes the more accidents on the roads.

- To recognize the road traffic population and inhabitants population in Hisar Tehsil.

- To obtain a model for the correlation between Traffic accidents and population in Hisar Tehsil with regression analysis method.

- To develop strategies to reduce the rate of accident.

- The aim of this research is to develop accident prediction model with the help of regression method and to combine spatially-based crash analyses and road safety investigations and to identify the major black spots for the road accidents as to give remedial measures. The scope of this research is limited to the crash data available for the limited period of time from 2001-2011. 


\section{FACTORS WHICH AFFECT THE ACCIDENTS IN HISAR}

\subsection{Situation of Weather}

Inconvenient weather conditions which affect the vehicle equipments are shown as

1. Humus or humidity

2. Condition in Temperature

3. Condition in Fog

4. Rain fall or fall

\subsection{Humanity Factor}

The prevalent portion in causing traffic accidents is the human factor. Human failure can be analyzed in two titles:

1. Self or personal effect

2. Psychologically effects

\section{Death Rate}

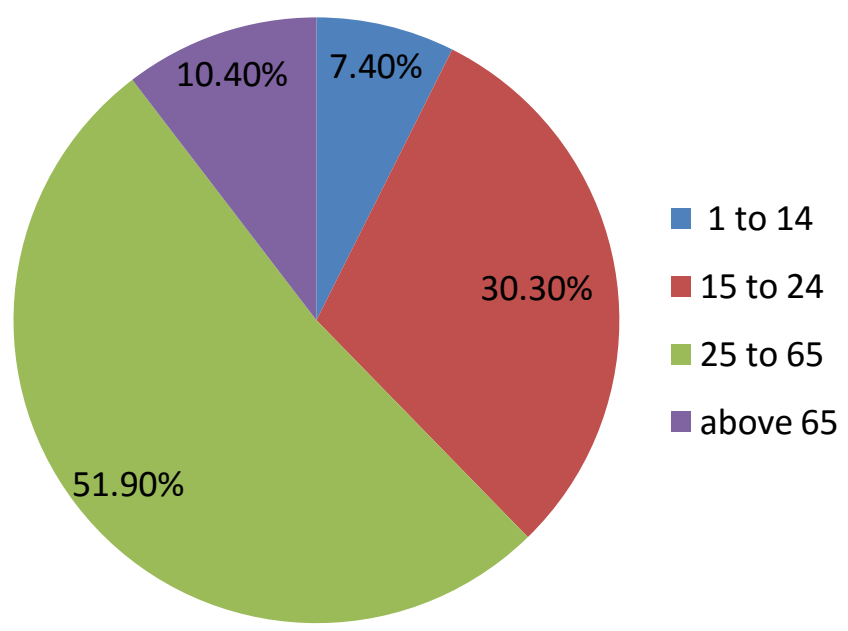

Figure 1. Pie chart of accident affected people on roads by age wise.

\section{BLACK SPOT LOCATION IN HISAR}

- $\quad \mathrm{NH} 10$ and NH 65, comprises the location of Black Spot near Hisar - Sirsa road near BSF Camp.

- Hisar- Balsamand road near filling station of Hindustan Petroleum.

- Bypass Road of Hisar- Delhi near Guru Jambheshwar University and near Hisar-Cantt road

\section{METHODOLOGY FOR STUDY}

\subsection{Regression Analysis}

The sample must be collected as population and accident and the assumptions are as:

- All the independent variable has to be independent of each other and no correlation is to carry out between them.

- For this all variables have to be normally distributed.
- Then all variables are continuous.

- Then a linear relationship occurs or exists between dependent and independent variable

- The constants can be solved in the following manner:

$\mathrm{Y}=\mathrm{a}+\mathrm{bX}$

$\mathrm{a}, \mathrm{b}=$ Output of regression

$\mathrm{Y}=$ Independent variable

$\mathrm{X}=$ Dependent variable

\section{DATA COLLECTION}

Table 1. Population of Hisar Tehsil

\begin{tabular}{|l|l|l|l|}
\hline TEHSIL/TALUKA & MALE & FEMALE & $\begin{array}{l}\text { TOTAL } \\
\text { POPULATION }\end{array}$ \\
\hline HISAR & 166623 & 140270 & 301249 \\
\hline ADAMPUR & 13452 & 12079 & 25531 \\
\hline AGROHA & 4068 & 3654 & 7722 \\
\hline BARWALA & 22593 & 20791 & 43384 \\
\hline TOTAL & 206736 & 176794 & 377886 \\
\hline
\end{tabular}

\subsection{Road Network of Haryana and Hisar}

The following data is showing the length of the road networks in Haryana and Hisar i.e. showing the length of National Highways, State Highways, MDR and ODR.

Table 2. Road Network of Haryana

\begin{tabular}{|l|l|}
\hline National Highways & $1957 \mathrm{~km}$ \\
\hline State Highways & $2064 \mathrm{~km}$ \\
\hline Major District Roads & $1455 \mathrm{~km}$ \\
\hline Other District Roads & $20287 \mathrm{~km}$ \\
\hline Total Length & $25763 \mathrm{~km}$ \\
\hline
\end{tabular}

Table 3. Road Network of Hisar Roads

\begin{tabular}{|l|l|}
\hline National Highways & $144 \mathrm{~km}$ \\
\hline State Highways & $193 \mathrm{~km}$ \\
\hline Major District Roads & $91 \mathrm{~km}$ \\
\hline Other District Roads & $1680 \mathrm{~km}$ \\
\hline Total Length & $2108 \mathrm{~km}$ \\
\hline
\end{tabular}




\section{GROWTH OF VEHICLES IN HISAR}

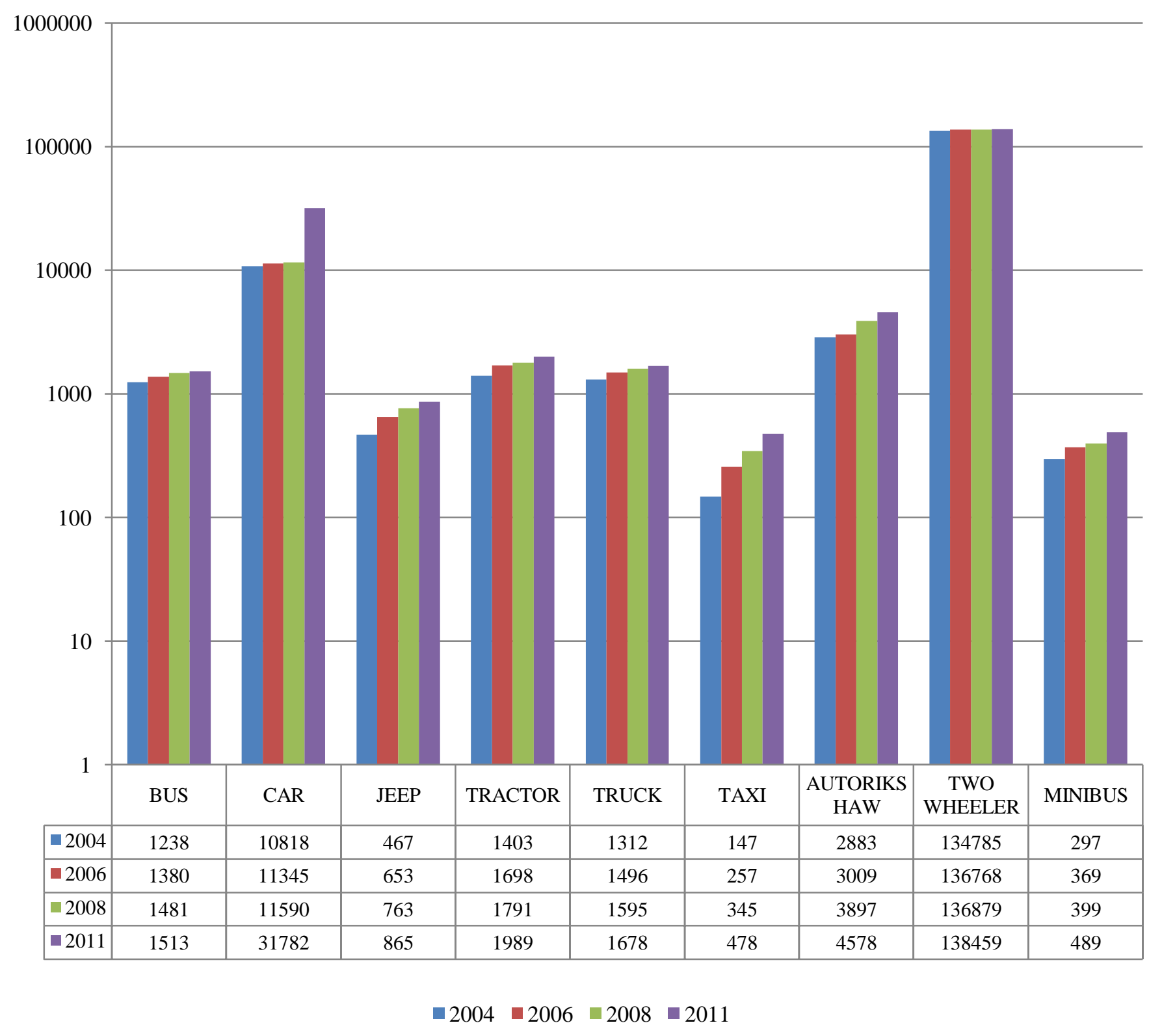

Figure 2. Growth of motor vehicles in Hisar from 2004 to 2011

Table 4. Year Wise Accidents from 2001 to 2010 in Hisar Tehsil

\begin{tabular}{|l|l|l|l|}
\hline Year & $\begin{array}{l}\text { Total } \\
\text { Accident }\end{array}$ & Death & Injured \\
\hline 2001 & 119 & 36 & 95 \\
\hline 2002 & 85 & 22 & 97 \\
\hline 2003 & 109 & 35 & 103 \\
\hline 2004 & 119 & 35 & 111 \\
\hline 2005 & 153 & 41 & 145 \\
\hline 2006 & 157 & 40 & 287 \\
\hline 2007 & 164 & 39 & 214 \\
\hline 2008 & 140 & 30 & 120 \\
\hline 2009 & 147 & 57 & 147 \\
\hline 2010 & 156 & 45 & 152 \\
\hline 2011 & 161 & 50 & 180 \\
\hline
\end{tabular}

Table 5. Name of Particular Accident Site Time in Hisar Tehsil

\begin{tabular}{|l|l|l|}
\hline Time & Day & Night \\
\hline National Highway & 448 & 101 \\
\hline State Highway & 211 & 51 \\
\hline Link Road & 615 & 84 \\
\hline Total & 1274 & 326 \\
\hline
\end{tabular}




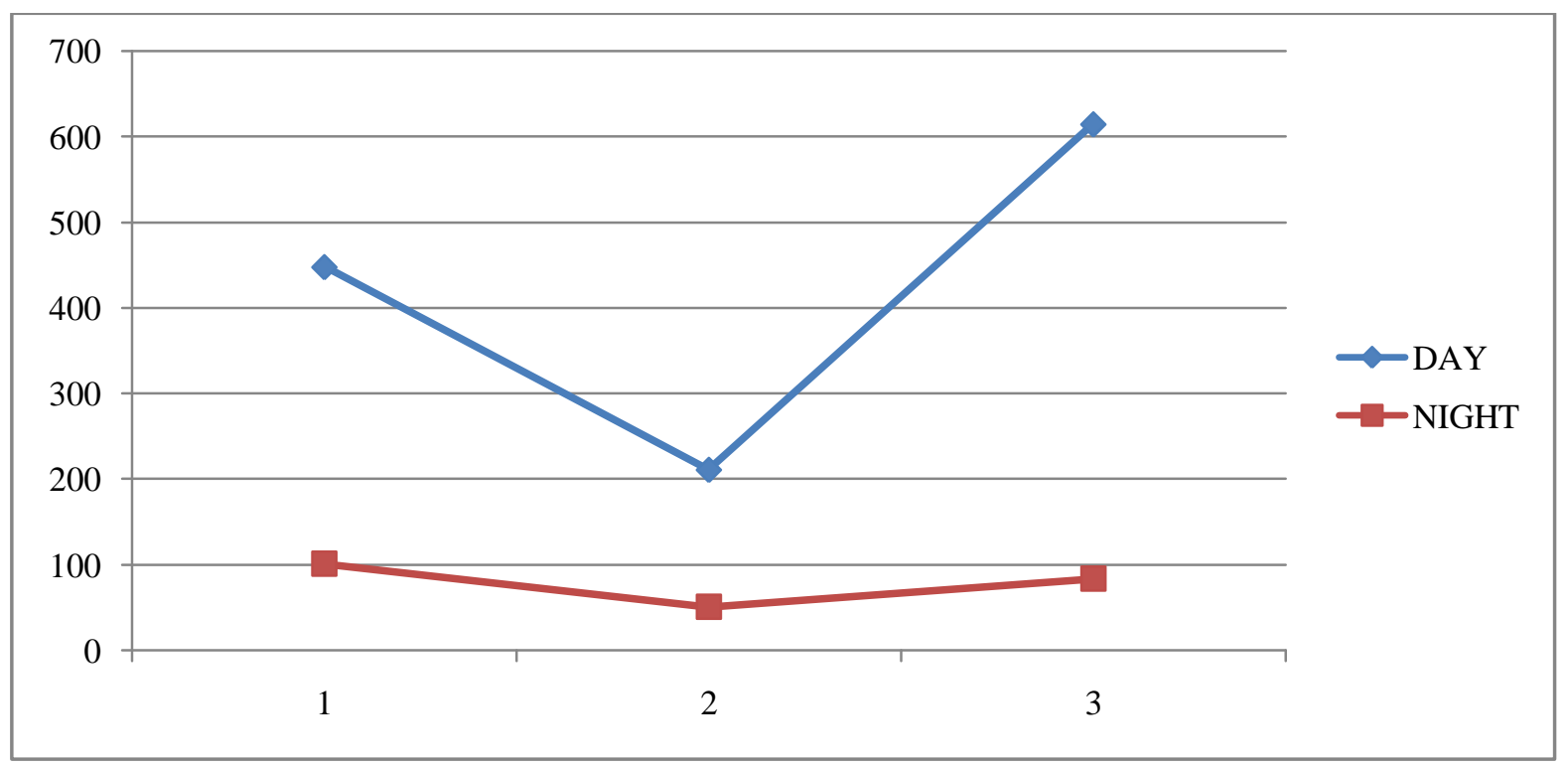

Figure 3. Line chart of accident time of Hisar Tehsil

\section{RESULT ANALYSIS}

7.1 The Layout of Hisar - Balsamand Road
The openings of two medians provide for the ease of filling petroleum at a distance of about 20 meters both sides. Therefore, the road users move in the mistaken way to fill the petroleum and as a result in raise in accidents.

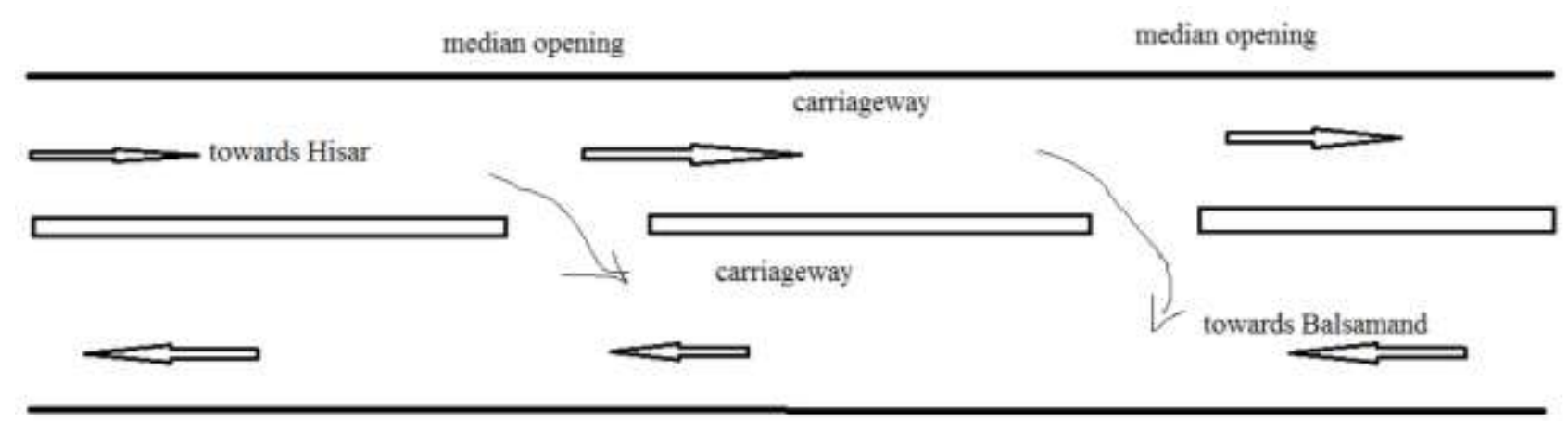

HINDUSTAN PETROLEUM

Figure 4. Shows the layout of the accident prone area on Hisar-Balsamand Road

\section{REMIDIAL MEASURES}

As we can see that there are two median openings available on both sides, so first of all it would be recommended to PWD to seal both median openings to reduce the accidents and provide the facility of petroleum filling capacity on other side too so that mainly in foggy conditions it will be creating less hazardous location.

Fog reflectors the use of fog reflectors is very important in that area because rain and fog reduce driver's ability to see the road and vehicles coming towards him. The car window always fogged up in these conditions. This area has very affected by rain and fog both dangerously and it's very important to install retro reflective safety device i.e. called as cat's eye also so as to reduce the accident rate on this road.

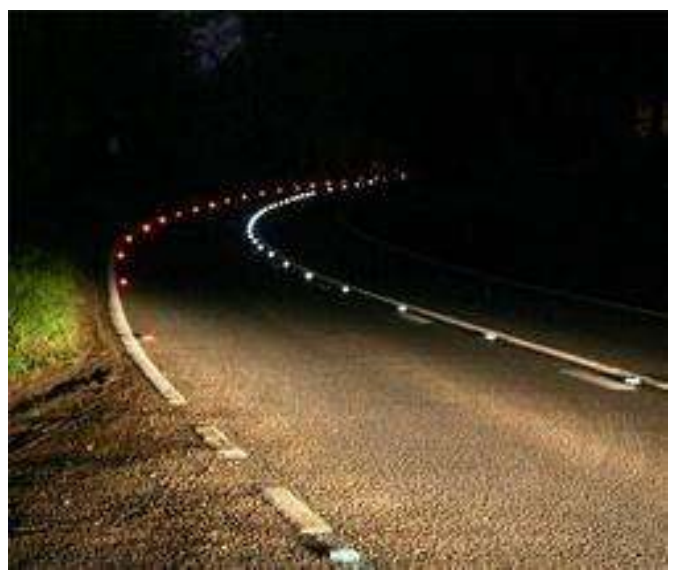

Figure 5. Shows how the road looks like after reflectors being installed 


\subsubsection{Condition of Road}

Various potholes found on this road that would be dangerous for the vehicles and people travelling on the road. The potholes would be properly fixed so as to decrease hazard situation on that road.

\section{REMEDIAL MEASURES}

To fix the potholes proper steps has to be taken:

Step 1 Clean the area to be repaired form loose materials or debris properly.

Step 2 Pour the QPR pothole repair directly from the container or machine.

Step 3 once we have approx a 2 inch base, use a tamp tool to compact the material in the hole.

Step 4after compacting the material, once again fill the QPR and compaction will either be done by bulldozers.

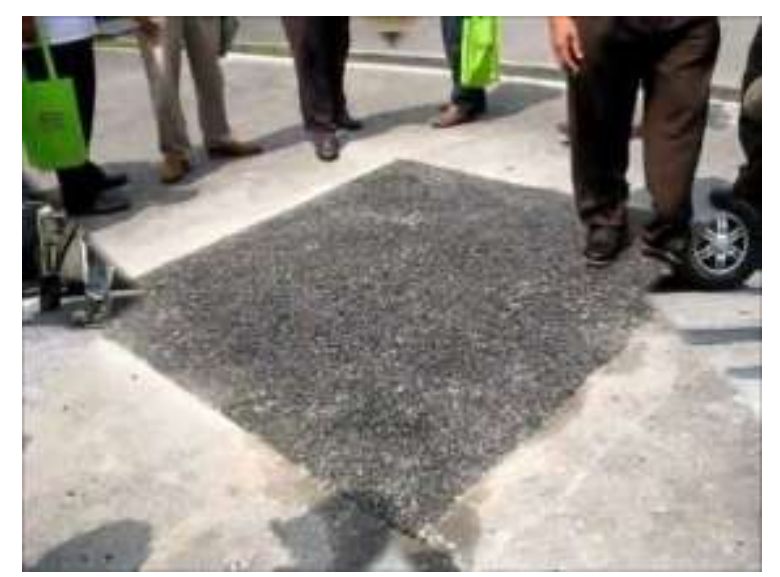

Figure 6. Shows how it looks like after repairing the pothole

\subsection{ANALYSIS OF HISAR- DELHI ROAD}

\subsubsection{Unavailability of Shoulders}

There is unavailability of shoulders and no proper safety guidance has provided.

\section{REMIDIAL MEASURES}

First of all there should be installed proper sign of low shoulder and construct the shoulders by Municipal Corporation of Hisar so that the accident prone site will be prevent.

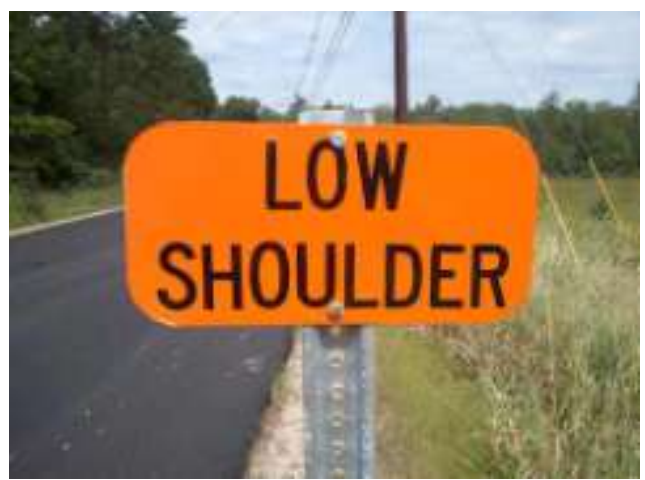

Figure 7. Shows how the proper sign should install for shoulders

\subsubsection{Unavailability of Road Markings}

There is no road markings available on these roads hence as a result accident prediction area will develop more and on that site many accident occur also.

\section{REMIDIAL MEASURES}

First of all provide road surface markings on these highways, provide centre lines for separation of traffic moving in opposite direction. As per IRC recommendations figure 8 and 9 shows the dimensions.

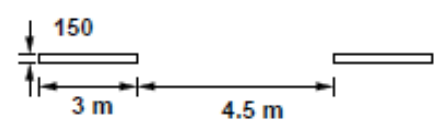

Figure 8. Centre line markings for two lane roads

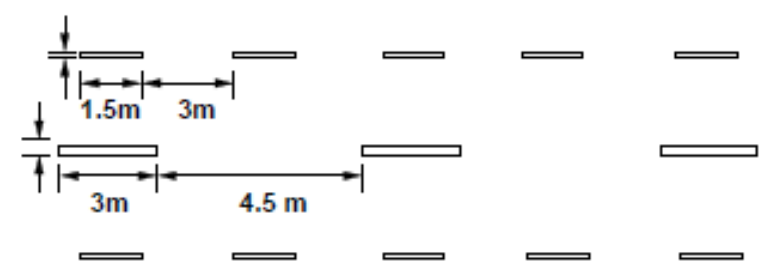

Figure 9. Centre line and lane markings for a four lane road

\subsection{EXPLORATORY DATA ANALYSIS} (REGRESSION ANALYSIS)

Table 6. Showing Population and Accident Relation Data

\begin{tabular}{|l|l|l|}
\hline Year & Accidents & Population \\
\hline 2001 & 119 & 280352 \\
\hline 2002 & 85 & 280652 \\
\hline 2003 & 109 & 289652 \\
\hline 2004 & 119 & 296560 \\
\hline 2005 & 153 & 301368 \\
\hline 2006 & 157 & 324598 \\
\hline 2007 & 164 & 347586 \\
\hline 2008 & 140 & 356376 \\
\hline 2009 & 147 & 358778 \\
\hline 2010 & 156 & 368476 \\
\hline 2011 & 161 & 377886 \\
\hline
\end{tabular}




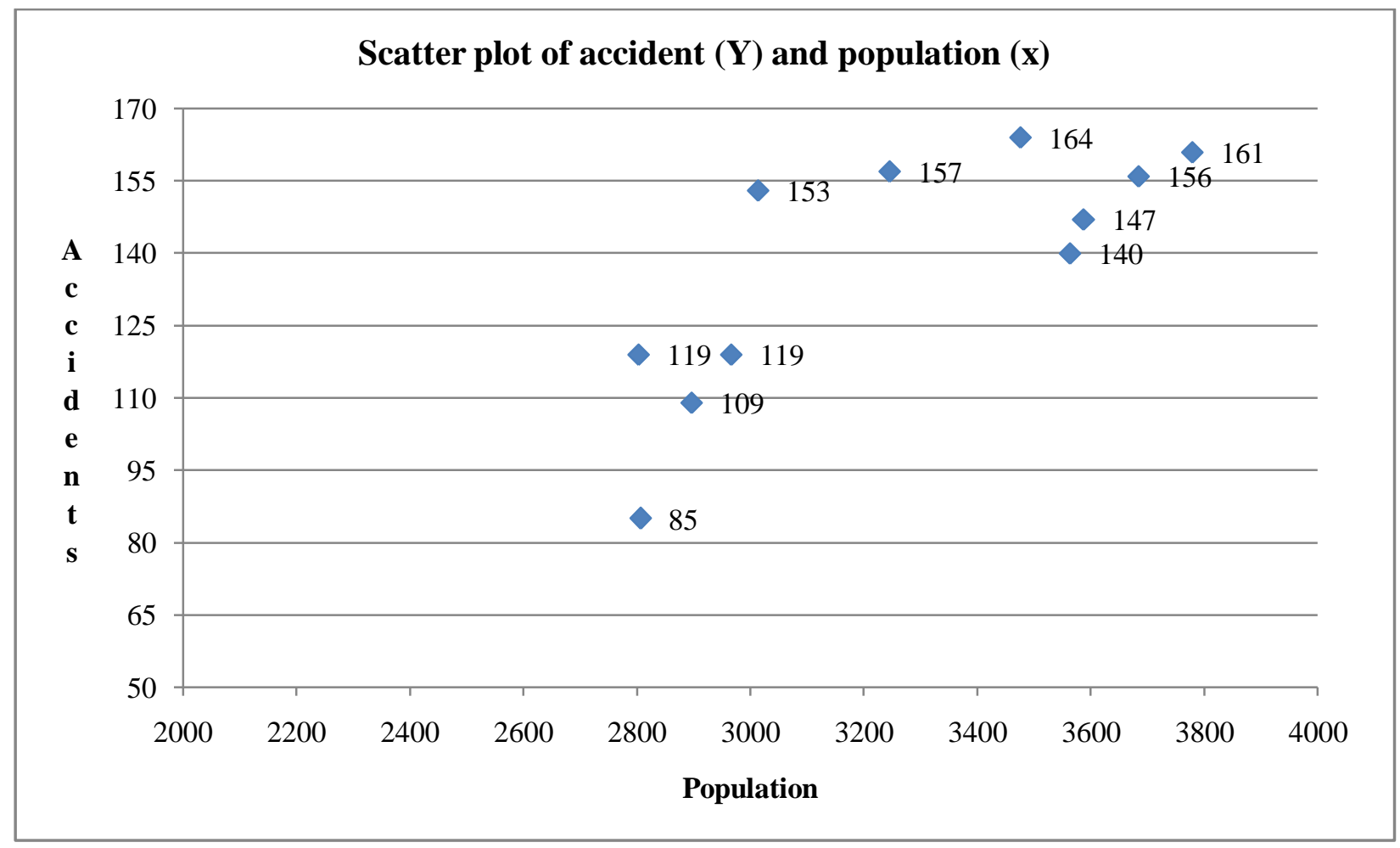

Figure 10. Shows the scatter plot of accidents and population in Hisar Tehsil

\section{SUMMMARY OUTPUTS: REGRESSION}

\section{STATISTICS}

Table 7. Summary Outputs of Regression data

\begin{tabular}{|l|l|}
\hline $\mathrm{R}$ Multiple & 0.770542329 \\
\hline $\mathrm{R}^{2}$ (R-sqr) & 0.59373548 \\
\hline Adjusted $\mathrm{R}^{2}$ & 0.548594978 \\
\hline Standard Error & 17.21629301 \\
\hline Observation & 11 \\
\hline
\end{tabular}

Table 8. Summary of regression coefficients

\begin{tabular}{|l|l|l|l|l|l|}
\hline Predictor & Coefficient & $\begin{array}{l}\text { Std.Error } \\
\text { Coefficient }\end{array}$ & $(\mathrm{P})$ & $\mathrm{R}^{2}$ & $\begin{array}{l}\mathrm{R}^{2} \\
\text { (adjusted) }\end{array}$ \\
\hline Intercept & -35.27 & 47.86 & 0.479 & 0.593 & 0.548 \\
\hline Pop x & 0.000529795 & 0.000146081 & 0.00551 & & \\
\hline
\end{tabular}

The regression model, which enhances the relationship between the population and total year wise accidents from the duration of 2001 to 2011 is thus given as:

$\mathrm{Y}=-\mathbf{3 5 . 2 7}+\mathbf{0 . 0 0 0 0 5 X}$

Y = Total no of accidents from period 2001-2011 $\underline{X}=$ Total Population by Year Wise.
The coefficient value of -35.27 is interpreted in the complete term will be the total number of year by year accidents when total population is set to be zero and all the added factors are seized as constant and at similar time as the coefficient of (X) 0.00005 is the rate of change in the no of hazards as a consequence of a transform in the Population. Yet for a second time, the coefficient value $(\mathrm{P})-35.27$ show that the regular term is irrelevant because it is superior than the selected Alpha level of 0.05 and at the similar time as that of the interpreter or predictor variable i.e. total yearly population ( $\mathrm{x}$ ) of 0.00551 shows an extremely important still however it is fairly less significant with roughly as zero (0) standard error. Additionally, $\mathrm{R}^{2}$ i.e. (R-Sq) called as Coefficient of Determination $59.3 \%$ shows that for the time beneath study based on the existing statistics, inhabitants (population) is capable to account for $59.3 \%$ of the change in hazards (accidents) in the Tehsil. The (R-adj) i.e. 54.8 show that the representation particularly has an illustrative influence of $54.8 \%$ completely adjusted for the degrees of freedom by means of consider to the Explanatory Variable.

ANOVA/ ANALYSIS OF VARIANCE: Anova is used to verify the hypothesis for this study and the data related to variance as shown below:

Table 9. Analysis of Variance

\begin{tabular}{|l|l|l|l|l|l|l|}
\hline Source & Df & SS & MS & F & Sig F & P \\
\hline Regressions & 1 & 3898.575114 & 3898.575114 & 13.1531 & 0.005513769 & 0.00551 \\
\hline Residual & 9 & 2667.606704 & 296.4007449 & & & \\
\hline Total & 10 & 6566.181818 & & & & \\
\hline
\end{tabular}


Null Hypothesis: According to null hypothesis we suppose that there is no considerable correlation between growth of Population in Hisar Tehsil and traffic accidents on roads.

Alternative Hypothesis: According to this, there is a considerable correlation among road traffic accident \& inhabitants growth in Hisar Tehsil.

Result: The value of $(\mathrm{P})$ in the analysis of variance table no. 9 has the value of 0.00551 . Shows that test is considerable at 0.05 and as an outcome e fail to allow the Null Hypothesis $\&$ discover that there is a great correlation between traffic accidents on roads and inhabitants (Populaion) in Hisar.

\subsection{ANALYSIS OF ACCIDENT STUDY}

\subsubsection{Population based on Death Rate}

Traffic accident to being in an area is articulated as the number of traffic victims per 100000 populations.

The formula is:

$\mathrm{R}=(B n \times 100000) / P$

$\mathrm{R}=$ Death Rate/ million Pop ${ }^{\mathrm{n}}$

$B n=$ Total no of accidents in a yr

$\mathrm{P}=\mathrm{Pop}^{\mathrm{n}}$ of the area

Table 10. Population based on Death Rate of Hisar Tehsil

\begin{tabular}{|l|l|l|l|}
\hline Year & $\begin{array}{l}\text { Total no of } \\
\text { traffic death } \\
\text { in a year } \\
(B n)\end{array}$ & Population (P) & $\begin{array}{l}\text { Death rate } \\
(\mathrm{R})\end{array}$ \\
\hline 2001 & 36 & 280352 & 12.83 \\
\hline 2002 & 22 & 280652 & 7.83 \\
\hline 2003 & 35 & 289652 & 12.08 \\
\hline 2004 & 35 & 296560 & 11.80 \\
\hline 2005 & 41 & 301368 & 13.60 \\
\hline 2006 & 40 & 324598 & 12.32 \\
\hline 2007 & 39 & 347586 & 11.22 \\
\hline 2008 & 30 & 356376 & 8.41 \\
\hline 2009 & 57 & 358778 & 15.88 \\
\hline 2010 & 45 & 368476 & 12.21 \\
\hline 2011 & 50 & 377886 & 13.23 \\
\hline
\end{tabular}

Indicates rate of death based on population of Hisar Tehsil from the period 2001- 2011, ranging between 7.83 and 15.88. It is indicating that death rate has variation with increasing or decreasing between the periods 2001-2011. This may be due to the fact that Hisar Municipal Corporation adopted and partially implemented recommendations and carried out improvements in geometric of the road- widening of roads, providing proper shoulders, installation of traffic control devices etc.

\subsubsection{Motor Vehicle Population Death Rate}

The traffic accident to being in an area can also be articulated as the no of traffic losses per 10000 vehicle register. The death rate reflects the revelation of accident for whole area and equal to pop $^{\mathrm{n}}$ based on death rate.

The formula is:

$\mathrm{R}=(B n \times 100000) / M n$
Where $\mathrm{R}=$ death rate/10000 vehicle registration

$B n=$ total no of traffic deaths in a year

$M n=$ no of motor vehicles register in an area

Table 11. Death rate based on motor vehicle population

\begin{tabular}{|l|l|l|l|}
\hline Year & $\begin{array}{l}\text { Total no of } \\
\text { traffic death } \\
\text { in a year }(B n)\end{array}$ & $\begin{array}{c}\text { Motor vehicle } \\
\text { population } \\
(\mathrm{Mn})\end{array}$ & $\begin{array}{l}\text { Death rate } \\
(\mathrm{R})\end{array}$ \\
\hline 2004 & 35 & 153350 & 22.82 \\
\hline 2006 & 40 & 156975 & 25.48 \\
\hline 2008 & 30 & 158740 & 18.89 \\
\hline 2011 & 50 & 181831 & 27.49 \\
\hline
\end{tabular}

Indicates rate of death based on motor vehicle population from the period 2004-2011, ranging between 18.89 and 27.49. It is indicating that death rate is increasing year by year as the population of motor vehicle increased. This may be due to lack of provision an endorsed to pitiable enlightenment and deficiency of caution measures such as delineation and cat eyes or retroreflective materials. The lack of improper road geometric designs would also be the main factor affected.

\section{CONCLUSIONS}

For the accident study on road, it can be accomplished to facilitate the accidents occurs in day time most as compare to night time, but the accident severity is very high in Hisar Tehsil. This may also be recognized to pitiable enlightenment during rain and fog in winter seasons most and unavailability of road markings and signs also and lack of caution measures such as delineations and retro-reflective objects. From the study it can be seen that growth of motor vehicles is also contributed to majority accidents and two wheelers have more contribution to accidents more this is because due to discontinues service road foremost to mistaken side movement of traffic to keep away from long detours. Badly planned and designed roads from the adjoining area of the highways are also foremost to more conflicts between neighboring traffic and weighty traffic like loaded by supplies. From the data mainly road parameters like shoulders, road markings, median opening, and carriageway conditions are main parameters of causing road accidents.

Based on analysis and interpretations, the theory exposed to facilitate that there is strong relationship between the road traffic accidents and inhabitants (Population) of Hisar Tehsil, particularly population enlargement accounts $59.30 \%$ of the changes in no of hazardous accidents in Hisar Tehsil. It shows that more accidents will rise as the population raise.

In the next attempt for the relationship was found to be $\mathbf{Y}=$ $-35.27+0.00005 X$ which is significant at $5 \%$ significance level and has a good fit as a model to help in future to forecast the accident occur with the relation of population of Hisar Tehsil. It is recommended that to further refine the model developed in this study with taken as various other 
variables to get more realistic image for predicting the accidents. But we cannot exactly predict future trends by using models and theories but it is a very handy tool for the planners to take remedial measures.

\section{REFERENCES}

[1] Analysis of Fatal Road Traffic Accidents in a Metropolitan City of South India, (2013), J Indian Acad Forensic Med. October-December, Vol. 35.

[2] Beenstock, Gafni, (2000), Globalization in road safety: explaining the downward trend in road accident rates in a single country (Israel). Journal of Accident Analysis and Prevention Vol. 32.

[3] Badami, M. G, Haider, (2007), an analysis of public bus transit performance in Indian cities.

[4] Dinesh, M. Ramamurthi, (2009), 'Road accidents in India', IATSS Research, vol. 33.

[5] E Madhu, B Sriniavasrao, (2005), Accident Study on National Highway, Between Anakapalli to Visakhapatnam, Proceedings Of The Eastern Asia Society For Transportation Studies, Vol. 5. 